\title{
ISOLAMENTO E PROSPECÇÃO DE BACTÉRIAS ENDOFÍTICAS E EPIFÍTICAS NA CANA-DE-AÇÚCAR EM ÁREAS COM E SEM CUPINICIDA ${ }^{(1)}$
}

\author{
Michelangelo de Oliveira Silva ${ }^{(2)}$, Fernando José Freire ${ }^{(3)}$, Mario Andrade Lira Junior ${ }^{(3)}$, \\ Júlia Kuklinsky-Sobral ${ }^{(4)}$, Diogo Paes da $\operatorname{Costa}^{(5)} \&$ Luana Lira-Cadete $^{(6)}$
}

\begin{abstract}
RESUMO
A exploração e o conhecimento dos mecanismos de interação bactéria-planta podem ser utilizados para a produção sustentável de diversas culturas, como a cana-de-açúcar. $O$ objetivo deste trabalho foi isolar e prospectar bactérias associadas à cultura da cana-de-açúcar com capacidade de fixar nitrogênio e solubilizar fosfato inorgânico em áreas com e sem aplicação de cupinicida. Bactérias endofíticas, de folha e raiz, e do rizoplano foram isoladas de três variedades comerciais (RB 92579, RB 867515 e RB 863129) de cana-de-açúcar, cultivadas no Nordeste brasileiro, em áreas com e sem aplicação de cupinicida, aos quatro meses após o plantio. Foram obtidos 272 isolados, selecionados quanto à sua capacidade de solubilizar fosfato inorgânico e fixar nitrogênio. O uso do cupinicida não provocou alterações nas comunidades microbianas endofíticas de folha e raiz e epifíticas do rizoplano. As variedades estudadas apresentam uma comunidade bacteriana associada com potencial aplicação para a promoção de crescimento vegetal, pois possuem a capacidade de fixar $\mathrm{N}_{2}$ e solubilizar fosfato inorgânico.
\end{abstract}

Termos de indexação: fixação de $\mathbf{N}_{2}$, solubilização de fosfato, endofíticas associativas, Saccharum sp.

(1) Parte da tese de Doutorado do primeiro autor apresentada ao Programa de Pós-Graduação em Ciência do Solo da Universidade Federal Rural de Pernambuco. Recebido para publicação em 16 de dezembro de 2011 e aprovado em 14 de junho de 2012.

(2) Engenheiro Agrônomo, Doutor em Ciência do Solo, Rua Delfin Moreira, 1178. Abolição, CEP 59619-200 Mossoró (RN). E-mail: angelo_ufrpe@yahoo.com.br

(3) Professor do Departamento de Agronomia da Universidade Federal Rural de Pernambuco, Rua Dom Manoel de Medeiros, s/ n, Dois Irmãos CEP 52171-900 Recife (PE). E-mail: f.freire@depa.ufrpe.br, mario.lira@depa.ufrpe.br. Bolsista de produtividade do CNPq.

(4) Professora Adjunta da Unidade Acadêmica de Garanhuns, Universidade Federal Rural de Pernambuco. Av. Bom Pastor, s/n, Boa Vista, CEP 55296-901 Garanhuns (PE). E-mail: jksobral@yahoo.com.br

(5) Engenheiro Agrônomo, Mestrando do Programa de Pós-Graduação em Solos e Nutrição de Plantas da ESALQ/USP. E-mail: diogocosta1@yahoo.com.br

(6) Discente de Agronomia da Unidade Acadêmica de Garanhuns, da Universidade Federal Rural de Pernambuco. E-mail: luanalirac@gmail.com 


\title{
SUMMARY: ISOLATION AND IDENTIFICATION OF ENDOPHYTIC AND EPIPHIYTIC BACTERIA IN SUGARCANE INAREAS WITH AND WITHOUT TERMITICIDE
}

\begin{abstract}
The exploration and knowledge of bacteria-plant interaction mechanisms may be used for a more sustainable production of several crops, e.g., of sugarcane. The objective of this paper was to isolate bacteria associated with sugarcane with the ability to fix nitrogen and solubilize inorganic phosphate in areas with and without the application of termiticide. Endophytic bacteria were isolated from leaves and roots and from the rhizoplane, four months after planting of three commercial sugarcane varieties (RB 92579, RB 867515 and $R B$ 863129), in the Northeast of Brazil. Altogether, 272 isolates were obtained and selected for their capacity to solubilize inorganic phosphate and fix nitrogen. Termiticide application induced no changes in the endophytic microbial communities of leaf and root and the epiphytic bacteria of the rhizoplane. A bacterial community associated with the studied sugarcane varieties was identified, which could be applied for plant growth promotion, since it can fix $N_{2}$ and solubilize inorganic phosphate.
\end{abstract}

Index terms: $\mathrm{N}_{2}$ fixation, phosphate solubilization, associated endophytic bacteria, Saccharum sp.

\section{INTRODUÇÃO}

A cana-de-açúcar (Saccharum sp.) é uma planta que ocupa posição de destaque entre as culturas de importância econômica nos cenários nacional e internacional. O Brasil é o maior produtor mundial, com safra estimada para 2010/11 em mais de 660 milhões de toneladas (Conab, 2011). Devido à importância dessa cultura, tem-se investido cada vez mais na manipulação genética dessas plantas e no estudo da diversidade microbiana associada. Esta última apresenta-se como importante alternativa para melhorar as características da planta e a sustentabilidade dessa cultura.

$\mathrm{Na}$ agricultura, existe um particular interesse na detecção da diversidade de bactérias que desempenham funções específicas no solo ou que vivem em associação com plantas, como as bactérias endofíticas associativas. Esse interesse deve-se ao fato de que as bactérias associativas podem promover o crescimento das plantas por meio da fixação biológica do N, pela solubilização de fosfato inorgânico ou pela produção de fito hormônios reguladores do crescimento de plantas. A exploração desse grupo microbiano em processos agrícolas poderia representar uma alternativa ao uso de fertilizantes sintéticos.

Estudos já demonstraram que a inoculação com bactérias associativas promotoras de crescimento de plantas aumentou o crescimento e produção de diversas culturas (Khalid et al., 2003; Richardson et al., 2009). Estudos de isolamento e seleção de isolados em diferentes espécies vegetais e em diversas regiões demonstram que a habilidade de algumas bactérias de produzir substâncias Promotoras de Crescimento de Plantas (PCPs) pode ser altamente específica a certas espécies de plantas, ou até mesmo de cultivares, como também a diferentes ambientes onde estão inseridos, ou, por sua vez, em decorrência do estresse pelo qual a comunidade possa estar passando devido a alterações ambientais e antropogênicas (Bergamashi, 2006; Mendes et al., 2007; Oliveira et al., 2009; Jha et al., 2009; Prakamhang et al., 2009).

As comunidades bacterianas são em sua maioria bastante complexas e sensíveis a alterações ambientais, bem como a alterações externas ao ambiente. Considerando as associações entre bactérias e plantas, estas podem ser sensíveis a alterações bióticas ou abióticas. As interações entre as diversas espécies bacterianas e as plantas determinam a composição das comunidades bacterianas, que são sensíveis, entre outros fatores, a alterações nos genótipos da planta, microrganismo, presença de patógeno ou aplicação de inseticidas, herbicidas, cupinicidas e fungicidas (Kuklinsky-Sobral, 2003).

Este trabalho teve como objetivo isolar bactérias associadas à cultura da cana-de-açúcar, bem como efetuar uma prospecção de bactérias com capacidade de fixar $\mathrm{N}$ e solubilizar fosfato inorgânico em áreas com e sem aplicação de cupinicida.

\section{MATERIAL E MÉTODOS}

\section{Coleta de Amostras}

Bactérias endofíticas, de folha e raízes, e bactérias do rizoplano foram isoladas de três variedades comerciais (RB 92579, RB 867515 e RB 863129) de cana-de-açúcar (Saccharum sp.), cultivadas na Estação Experimental de Cana-de-Açúcar de Carpina/ PE (EECAC), da Universidade Federal Rural de Pernambuco (UFRPE), e em área experimental da usina Petribu, no município de Lagoa de Itaenga/PE, assim como amostras de solo da região do rizoplano dessas variedades no ciclo de cana-planta. A coleta ocorreu nas variedades que estavam sendo cultivadas em campo, em solos com características e manejo diferenciados, em áreas onde se aplicava cupinicida 
(usina Petribu) e em que não se aplicava cupinicida (EECAC). As amostras vegetais, quatro plantas de cada variedade, foram coletadas entre quatro e cinco meses de cultivo, sendo identificadas e levadas a laboratório para processamento das análises.

\section{Isolamento de Bactérias Associadas à Cana- de-Açúcar}

Após a coleta, as amostras vegetais foram lavadas em água corrente e separadas em folhas e raízes; posteriormente, foi realizada uma desinfecção do material para eliminar a comunidade epifítica cultivável dos tecidos vegetais. $\mathrm{O}$ isolamento de bactérias do rizoplano e endofíticas das folhas e das raízes foi realizado de acordo com Kuklinsky-Sobral et al. (2004) e Mendes et al. (2007). Foi utilizado o meio TSA $10 \%$ (Tripcase Soy Agar), com modificações, suplementado com o fungicida Cercobyn $700\left(50 \mathrm{\mu g} \mathrm{m} \mathrm{L}^{-1}\right)$; as placas de Petri foram incubadas a $28^{\circ} \mathrm{C}$ e avaliadas após 3 , 8 e 14 dias.

A população bacteriana por grama de tecido vegetal fresco (UFC/g TVF) foi estimada pela contagem de colônias cultivadas em meio TSA. Colônias características de cada tipo morfológico foram repicadas das placas de isolamento, purificadas e mantidas em TSA $10 \%$ líquido suplementado com $20 \%$ de glicerol a $-20^{\circ} \mathrm{C}$, para formação e organização de uma coleção de culturas bacterianas associadas a variedades de cana-de-açúcar cultivadas no Nordeste.

\section{Seleção de Bactérias Fixadoras de Nitrogênio}

A seleção de bactérias fixadoras de $\mathrm{N}$ foi realizada segundo Dobereiner et al. (1995). Para isso, as bactérias foram inoculadas em meio semissólido $\mathrm{NFb}$ [ $5 \mathrm{~g} \mathrm{~L}^{-1}$ de ácido málico; $0,5 \mathrm{~g} \mathrm{~L}^{-1}$ de $\mathrm{K}_{2} \mathrm{HPO}_{4} ; 0,2 \mathrm{~g} \mathrm{~L}^{-1}$ de $\mathrm{MgSO}_{4} .7 \mathrm{H}_{2} \mathrm{O} ; 0,1 \mathrm{~g} \mathrm{~L}^{-1}$ de NaCl; $0,01 \mathrm{~g} \mathrm{~L}^{-1}$ de $\mathrm{CaCl}_{2} \cdot 2 \mathrm{H}_{2} \mathrm{O} ; 4 \mathrm{~mL} \mathrm{~L}^{-1}$ de Fe-EDTA (solução $1,64 \%$ ); $2 \mathrm{~mL} \mathrm{~L}^{-1}$ de azul de bromotimol (0,5\%); $2 \mathrm{~mL} \mathrm{~L}^{-1}$ de solução de micronutrientes $\left(0,2 \mathrm{~g} \mathrm{~L} \mathrm{~L}^{-1}\right.$ de

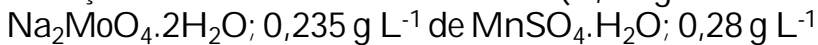
de $\mathrm{H}_{3} \mathrm{BO}_{3} ; 0,008 \mathrm{~g} \mathrm{~L}^{-1}$ de $\left.\mathrm{CuSO}_{4} \cdot 5 \mathrm{H}_{2} \mathrm{O}\right) ; 1,75 \mathrm{~g} \mathrm{~L}^{1} \mathrm{de}$ ágar; e pH 6,8], incubadas a $28^{\circ} \mathrm{C}$, por oito dias. Os experimentos foram realizados em triplicatas, e os resultados positivos foram caracterizados pela presença de um halo de crescimento no interior do meio de cultura. O procedimento foi repetido novamente, para verificação da real função de fixação.

\section{Seleção de Bactérias Solubilizadoras de Fosfato Inorgânico}

A seleção de bactérias solubilizadoras de fosfato inorgânico foi feita segundo Verma et al. (2001) e Rodriguez et al. (2000), com algumas modificações. As bactérias foram inoculadas em meio VERMA modificado contendo fosfato insolúvel $\left(10 \mathrm{~g} \mathrm{~L}^{-1} \mathrm{de}\right.$ glicose; $5 \mathrm{~g} \mathrm{~L}^{-1}$ de $\mathrm{NH}_{4} \mathrm{Cl} ; 1 \mathrm{~g} \mathrm{~L}^{-1}$ de NaCl; $1 \mathrm{~g} \mathrm{~L}^{-1}$ de $\mathrm{MgSO}_{4} .7 \mathrm{H}_{2} \mathrm{O} ; 4 \mathrm{~g} \mathrm{~L}^{-1} \mathrm{de} \mathrm{CaHPO}_{4} ; 15 \mathrm{~g} \mathrm{~L}^{-1}$ de ágar; $\mathrm{e}$ $\mathrm{pH} 7,2$ ). As placas foram inoculadas a $28^{\circ} \mathrm{C}$, por $72 \mathrm{~h}$ e, em seguida, realizaram-se as leituras. Os experimentos foram realizados em triplicatas, e a presença de um halo claro em torno da colônia indicou a solubilização do fosfato.

\section{Análise Estatística}

Os dados foram submetidos a uma comparação pelo teste t a $5 \%$ entre os fatores variedade e tecido vegetal. $\mathrm{O}$ teste do qui-quadrado $\left(\chi^{2}\right)$ foi utilizado para comparar a proporção de fixadores e solubilizadores entre as origens das estirpes, ou seja, as diferentes cultivares, presença/ausência de cupinicida e as partes da planta e rizoplano, a $10 \%$ de probabilidade.

\section{RESULTADOS E DISCUSSÃO}

As presenças de bactérias endofíticas e epifíticas de folhas e raízes de três variedades de cana-de-açúcar foram determinadas aos quatro meses do desenvolvimento vegetal de cana-planta em solos manejados na presença e ausência de cupinicida, na safra 2008/09. Durante as avaliações não foi observado crescimento bacteriano nas placas do controle da desinfecção superficial, mostrando que o método utilizado eliminou a comunidade epifítica cultivável dos tecidos vegetais.

A densidade populacional da comunidade de bactérias endofíticas de folhas e raízes e epifíticas do rizoplano nas variedades de cana-de-açúcar (RB 92579, RB 867515 e RB 863129), aos quatro meses de desenvolvimento da planta e sem aplicação de cupinicida, variou de $10^{2}$ a $10^{9} \mathrm{UFC} / \mathrm{g}$ de TVF (Quadro 1). Todavia, a aplicação de cupinicida não influenciou a densidade populacional dessa comunidade a ponto de promover alterações que chegassem a ser notadas pela análise estatística. Uma possível resposta é que a dose de $200 \mathrm{~g} \mathrm{ha}^{-1}$ aplicada na região não foi suficiente para promover alterações na comunidade bacteriana.

No entanto, pode-se observar que na região do rizoplano é onde se localizam os maiores valores de densidade populacional; o interessante é que esses números são maiores onde houve aplicação do cupinicida. Por outro lado, a variedade RB 863129 , independentemente da região ou do tecido, alcança maiores valores de densidade populacional, os quais se encontram na região do rizoplano (Quadro 1). Isso pode ser atribuído às exigências nutricionais da planta, que mudam em cada estádio de desenvolvimento: é maior nos primeiros meses na região onde se encontram as raízes, e, no decorrer do seu desenvolvimento vegetal, as bactérias passam a migrar e se estabelecer em outras regiões para acompanhar esse deslocamento de nutrientes, ou pela sua colonização preferencial de tecidos (Reis Junior et al., 2000). Esse fato sugere que as plantas possuem capacidade de suporte desses microrganismos mesmo 
que os grupos microbianos sejam distintos para as diferentes regiões, como também para cada genótipo. Nas condições avaliadas, o cupinicida não influenciou a comunidade bacteriana associada à cana-de-açúcar. Este estudo suporta estudos anteriores realizados com tabaco. Apesar de espécies de plantas totalmente diferentes, deve-se ressaltar aqui apenas o comportamento dos microrganismos, em que a comunidade microbiana é influenciada apenas nos estádios iniciais do desenvolvimento da planta, havendo efeito transiente, que é neutralizado em estádios posteriores (Andreote, 2007).

Aos quatro meses de desenvolvimento da cultura, principalmente nos estádios iniciais, a densidade de bactérias na região das raízes foi maior que nas folhas (Quadro 1). Esse padrão de distribuição da comunidade, no qual as partes inferiores da planta hospedam maior frequência de endófitos, segue o mesmo padrão de colonização de bactérias endofíticas isoladas em outras condições com a canade-açúcar (Mendes et al., 2007; Oliveira et al., 2009) e no sorgo (Bergamashi, 2006) e arroz (Jha et al., 2009; Prakamhang et al., 2009). Isso deve-se ao fato de que essa região é o local onde ficam mais concentrados os compostos exsudados pelas raízes das plantas, carregados de fontes de energia e de nutrientes necessários para os ciclos das células bacterianas.

A colonização preferencial de bactérias endofíticas e epifíticas na região das raízes reflete a presença de altos níveis de nutrientes disponíveis, como $\mathrm{P}, \mathrm{K}$, $\mathrm{Mg}, \mathrm{B}, \mathrm{Zn}$, Mo e outros localizados na rizosfera e rizoplano, os quais podem ser utilizados para o crescimento e metabolismo bacterianos (Cocking, 2003; Medeiros et al., 2006). Bactérias endofíticas e epifíticas foram localizadas principalmente nas raízes, apresentando gradiente decrescente das raízes às folhas. Além disso, pode-se sugerir que a principal região de entrada dos endófitos sejam as raízes e regiões basais do hospedeiro - a partir daí, elas podem se disseminar no interior da planta. Resultados semelhantes foram encontrados nas culturas de cana-de-açúcar, soja e arroz em outros trabalhos de pesquisa (Kuklinsky-Sobral et al., 2004; Oliveira et al., 2009; Jha et al., 2009). A colonização preferencial de bactérias endofíticas e epifíticas na região das raízes refletem a presença de altos níveis de nutrientes na rizosfera e rizoplano, os quais podem ser utilizados para o crescimento e metabolismo bacterianos (Melloni et al., 2004; Oliveira et al., 2009).

Pode-se argumentar que durante essa fase as populações bacterianas estão bem estabelecidas e, sob condições favoráveis, o seu nível populacional não pode ser influenciado pelo cupinicida; em determinados casos houve crescimento da população (Quadro 1), mas acredita-se que por outros motivos de exigência nutricional e devido à preferência dos grupos bacterianos por outras regiões da planta. Esses resultados divergem dos encontrados por ParionaLlanos et al. (2010), quando estudaram a influência de fertilizantes orgânicos no isolamento de bactérias endofiticas diazotróficas em cana-de-açúcar sem o uso de cupinicida.

De certa forma, alguns dos fatores analisados manejo de insumos agrícolas e cultivares do hospedeiro - apresentaram pouca ou nenhuma influência sobre a

Quadro 1. Densidade populacional total da comunidade bacteriana endofítica da folha e raiz e epifítica do rizoplano de diferentes variedades de cana-de-açúcar, na presença e ausência de cupinicida, aos quatro meses de idade, média e F das variáveis

\begin{tabular}{|c|c|c|c|}
\hline \multicolumn{2}{|c|}{ Fator } & \multicolumn{2}{|c|}{ Densidade Total } \\
\hline \multirow[t]{2}{*}{ Região } & Variedade & Sem cupinicida & Com cupinicida \\
\hline & RB 92579 & 3,02 & 3,85 \\
\hline \multirow[t]{3}{*}{ Folha } & RB 867515 & 3,92 & 2,56 \\
\hline & RB 863129 & 4,18 & 4,09 \\
\hline & RB 92579 & 6,09 & 5,64 \\
\hline \multirow[t]{3}{*}{ Raiz } & RB 867515 & 5,43 & 5,67 \\
\hline & RB 863129 & 6,88 & 7,16 \\
\hline & RB 92579 & 8,65 & 8,32 \\
\hline \multirow[t]{4}{*}{ Rizoplano } & RB 867515 & 8,39 & 9,20 \\
\hline & RB 863129 & 8,66 & 9,53 \\
\hline & & 6,14 & 6,22 \\
\hline & & & \\
\hline
\end{tabular}

ns: não significativo. 
densidade populacional das comunidades bacterianas endofíticas e epifíticas, porém mostraram influência sobre a diversidade de grupos bacterianos.

Foram avaliados 272 isolados bacterianos provenientes de amostragens em diferentes regiões da cana-de-açúcar e do rizoplano quanto ao potencial para fixar $\mathrm{N}_{2}$, por meio de cultivo em meio seletivo $\mathrm{NFb}$, dos quais 140 foram isolados em manejo de cultivo de cana-de-açúcar sem aplicação de cupinicida e $132 \mathrm{em}$ manejo com cupinicida. Constatou-se que 56 e $52 \%$, respectivamente, dos isolados foram capazes de crescer em meio $\mathrm{NFb}$, apresentando, portanto, potencial para fixar $\mathrm{N}_{2}$ independentemente da presença ou ausência de cupinicida no manejo da cultura, embora afirmações mais conclusivas quanto ao efeito do cupinicida dependam de novos estudos com outros produtos e doses.

Não se observou diferença nos isolados bacterianos sem capacidade de fixar $\mathrm{N}_{2}$ e solubilizar fosfato entre as regiões, independentemente da presença ou ausência de cupinicida. Contudo, a variedade que apresentou diferença em sua frequência relativa foi a RB 92579, com relação à aplicação do cupinicida (Quadro 2).

$\mathrm{O}$ teste do $\chi^{2}$ mostrou diferença nas frequências relativas para os isolados bacterianos epifiticos, quanto à capacidade de fixar $\mathrm{N}_{2}$, na ausência ou presença da aplicação do cupinicida; essa diferença só ocorreu para a variedade RB 863129 na ausência/presença do cupinicida (Quadro 2).

A fixação biológica de $\mathrm{N}_{2}$ tem sido um dos mecanismos explorados na interação microrganismosplanta em diversos estudos (Cocking, 2003; Kuklinsky-Sobral et al., 2004; Medeiros et al., 2006). Em cana-de-açúcar, os estudos têm se concentrado em variedades de cana cultivadas na região Sudeste do País e encontrado importantes grupos bacterianos que desempenham a fixação biológica do nitrogênio (FBN) (Polidoro et al., 2006). Portanto, os isolados encontrados reforçam o fato de que bactérias associadas à cana-de-açúcar representam uma relação microrganismos-planta importante para o desenvolvimento da planta hospedeira.

Os isolados bacterianos retirados das áreas sem e com aplicação de cupinicida foram testados também em relação à solubilização de fosfato inorgânico, tendose constatado que 36 e $41 \%$, respectivamente, foram capazes de solubilizar fosfato inorgânico. Assim, podese inferir que a solubilização de fosfato inorgânico pelas colônias de bactérias não dependem da presença de cupinicida.

Não foram observadas diferenças nos isolados bacterianos com capacidade de solubilizar fosfato, bem como nos isolados com capacidade de fixar $\mathrm{N}_{2}$ e solubilizar fosfato, entre as regiões, independentemente da presença ou ausência de cupinicida (Quadro 3). Entretanto, foi possível observar que os isolados bacterianos provenientes das variedades mostraram diferentes capacidades de solubilizar fosfato inorgânico, dependendo da variedade e região da planta (Quadro 3), destacando-se a variedade $R B$ 863129 na ausência de cupinicida e a variedade RB 867515 na presença deste. Quando se avaliou a capacidade de solubilizar fosfato inorgânico, constatouse diferença nas frequências relativas dos isolados bacterianos endofíticos e epifíticos; neste último grupo foi encontrada a maioria dos isolados bacterianos solubilizadores de fosfato inorgânico, independentemente da presença ou ausência de cupinicida (Figura 3). Essa diferença é mais evidente apenas para a variedade RB 867515.

$\mathrm{O}$ fósforo $(\mathrm{P})$, um dos principais nutrientes limitantes do crescimento vegetal, é rapidamente imobilizado após a adição ao solo como adubo solúvel, tornando-se indisponível para a planta. Também nesse aspecto, a atividade bacteriana é extremamente importante no que diz respeito ao fornecimento de $\mathrm{P}$ às plantas. Endófitos são conhecidos por promoverem crescimento da planta por meio de solubilização de fosfato (Verma et al., 2001; Wakelin et al., 2004; Collavino et al., 2010). Nesse aspecto, a observação de maior frequência de bactérias solubilizadoras de fosfato inorgânico na região da folha e do rizoplano sugere que esse grupo de bactérias poderia ter papel mais importante durante essa fase do desenvolvimento da planta hospedeira, dependendo do genótipo da planta.

O uso do cupinicida não influenciou as bactérias com capacidade de solubilizar fosfato inorgânico, porém mais estudos, levando-se em consideração concentrações diferentes do produto, devem ser realizados. Resultados semelhantes a esses foram encontrados por Reis et al. (2008), estudando a ação de herbicidas em microrganismo de solo rizosférico de cana-de-açúcar.

Com a inoculação no solo de bactérias com capacidade de solubilizar fosfato, pode haver solubilização do P que esteja em uma forma que a planta não consiga absorver e, ou, precipitado, e isso pode resultar em melhor desenvolvimento das plantas e da sua capacidade produtiva (Canbolat et al., 2009; Dias et al., 2009). Tendo em vista que bactérias endofíticas colonizam o interior da planta hospedeira e o fosfato inorgânico está no solo, é viável especular que bactérias endofíticas, durante seu processo de colonização da planta, possam solubilizar e aumentar a disponibilidade de fosfato à planta hospedeira (Rodriguez et al., 2000; Massenssini et al., 2008; Reis, et al., 2008; Postma et al., 2010).

Para os isolados que realizam as funções de fixar $\mathrm{N}_{2}$ e solubilizar fosfato, o teste do $\chi^{2}$ só apresentou diferença em suas frequências relativas para as bactérias epifíticas e para a variedade RB 863129 . É importante ressaltar a importância dessa informação, já que, como essa é a principal via de infecção desses microrganismos e como a maior concentração dos nutrientes ocorre justamente 
próximo dessa região, isso pode acarretar maior disponibilidade para a planta, nos primeiros meses. Para nossa região produtora de cana-de-açúcar, onde $90 \%$ dos solos são mais intemperizados e o $\mathrm{P}$ é o nutriente limitante, além do motivo mencionado, há também o relevo da região, que força a prática abusiva da adubação desse nutriente, aumentando as perdas, o que o torna indisponível para a planta por diversos mecanismos. Todavia, tem-se buscado selecionar bactérias que apresentem mais de uma característica envolvida com a promoção de crescimento vegetal (Verma et al., 2001; Shi et al., 2009). A capacidade de bactérias para solubilizar fosfato inorgânico também é um fator envolvido na interação bactériaplanta, pois essa característica aumenta a disponibilidade de $\mathrm{P}$ disponível, sendo esse um possível mecanismo de promoção de crescimento vegetal em campo.

Quadro 2. Número e frequência relativa (\%) dos isolados sem capacidade de fixar $\mathbf{N}_{2}$ e solubilizar fosfato e dos que possuem a capacidade de fixar de $\mathrm{N}_{2}$ dos isolados bacterianos endofíticos e epifíticos de três variedades de cana-de-açúcar, aos quatro meses de idade, no ciclo de cana-planta, na presença e na ausência de cupinicida. Teste do $\chi^{2}(\mathbf{p}<0,05)$

\begin{tabular}{|c|c|c|c|c|c|c|c|}
\hline \multicolumn{2}{|c|}{ Fator } & \multicolumn{2}{|c|}{ Frequência Relativa } & \multicolumn{2}{|c|}{ Fator } & \multicolumn{2}{|c|}{ Frequência Relativa } \\
\hline Região & Variedade & $\begin{array}{c}\text { Sem } \\
\text { Cumprida }\end{array}$ & $\begin{array}{c}\text { Com } \\
\text { Cumprida }\end{array}$ & Variedade & Região & $\begin{array}{c}\text { Sem } \\
\text { Cumprida }\end{array}$ & $\begin{array}{c}\text { Com } \\
\text { Cumprida }\end{array}$ \\
\hline & & \multicolumn{2}{|c|}{ - Un. $(\%)^{(1)}$} & & & \multicolumn{2}{|c|}{ - Un. $(\%)$} \\
\hline \multicolumn{8}{|c|}{ Isolados sem fixação e solubilização } \\
\hline \multirow{3}{*}{ Folha } & RB 92579 & $10(38)$ & $12(48)$ & RB 92579 & Folha & $10(48)$ & $12(54)$ \\
\hline & RB 867515 & $6(24)$ & $7(28)$ & & Raiz & $10(48)$ & $5(23)$ \\
\hline & RB 863129 & $10(38)$ & $6(24)$ & & Rizoplano & $1(4)$ & $5(23)$ \\
\hline \multicolumn{2}{|c|}{$\chi^{2}$} & \multicolumn{2}{|c|}{$1,000^{\mathrm{n} . \mathrm{s}}$} & \multicolumn{2}{|c|}{$\chi^{2}$} & \multicolumn{2}{|c|}{$2,667^{\circ}$} \\
\hline & RB 92579 & $10(50)$ & $5(31)$ & RB 867515 & Folha & $6(37)$ & $7(64)$ \\
\hline \multirow[t]{2}{*}{ Raiz } & RB 867515 & $6(30)$ & $3(19)$ & & Raiz & $6(37)$ & $3(27)$ \\
\hline & RB 863129 & $4(20)$ & $8(50)$ & & Rizoplano & $4(26)$ & $1(9)$ \\
\hline \multicolumn{2}{|c|}{$\chi^{2}$} & \multicolumn{2}{|c|}{$1,333^{\text {n.s }}$} & \multicolumn{2}{|c|}{$\chi^{2}$} & \multicolumn{2}{|c|}{$1,800^{\mathrm{n} . \mathrm{s}}$} \\
\hline \multirow{3}{*}{ Rizoplano } & RB 92579 & $1(13)$ & $5(72)$ & RB 863129 & Folha & $10(59)$ & $6(40)$ \\
\hline & RB 867515 & $4(50)$ & $1(14)$ & & Raiz & $4(23)$ & $8(53)$ \\
\hline & RB 863129 & $3(37)$ & $1(14)$ & & Rizoplano & $3(18)$ & $1(7)$ \\
\hline \multicolumn{2}{|c|}{$\chi^{2}$} & \multicolumn{2}{|c|}{$1,000^{\mathrm{n} . \mathrm{s}}$} & \multicolumn{2}{|c|}{$\chi^{2}$} & \multicolumn{2}{|c|}{$1,000^{\text {n.s }}$} \\
\hline \multicolumn{8}{|c|}{ Isolados fixadores de nitrogênio } \\
\hline \multirow{3}{*}{ Folha } & RB 92579 & $4(25)$ & $5(31)$ & RB92579 & Folha & $4(16)$ & $5(22)$ \\
\hline & RB 867515 & $7(44)$ & $6(38)$ & & Raiz & $5(20)$ & $7(32)$ \\
\hline & RB 863129 & $5(31)$ & $5(31)$ & & Rizoplano & $16(64)$ & $10(45)$ \\
\hline \multicolumn{2}{|c|}{$\chi^{2}$} & \multicolumn{2}{|c|}{$0,000^{\text {n.s }}$} & \multicolumn{2}{|c|}{$\chi^{2}$} & \multicolumn{2}{|c|}{$1,385^{\mathrm{n} . \mathrm{s}}$} \\
\hline \multirow{3}{*}{ Raiz } & RB 92579 & $5(29)$ & $7(29)$ & RB867515 & Folha & $7(32)$ & $6(22)$ \\
\hline & RB 867515 & $3(18)$ & $9(38)$ & & Raiz & $3(14)$ & $9(33)$ \\
\hline & RB 863129 & $9(53)$ & $8(33)$ & & Rizoplano & $12(54)$ & $12(45)$ \\
\hline \multicolumn{2}{|c|}{$\chi^{2}$} & 0,05 & & & & 0,00 & $0^{\text {n.s }}$ \\
\hline & RB 92579 & $16(35)$ & $10(34)$ & RB863129 & Folha & $5(16)$ & $5(25)$ \\
\hline Rizoplano & RB 867515 & $12(26)$ & $12(41)$ & & Raiz & $9(28)$ & $8(40)$ \\
\hline & RB 863129 & $18(39)$ & $7(25)$ & & Rizoplano & $18(56)$ & $7(35)$ \\
\hline & & 4,84 & & $\gamma$ & & 4,840 & \\
\hline
\end{tabular}

(1) Unidade (Un.): representação do valor fora dos parênteses; e percentagem (\%): representação do valor unitário em percentual. ${ }^{\text {ns }} \mathrm{e}^{*}$ : não sifnificativo e significativo a $5 \%$, respectivamente. 
Quadro 3. Número de isolados e sua frequência relativa (\%) dos isolados com capacidade de solubilizar fosfato e dos que fixam $\mathrm{N}_{2}$ e solubilizam fosfato dos isolados bacterianos endofíticos e epifíticos de três variedades de cana-de-açúcar, aos quatro messes de idade, no ciclo de cana-planta, na presença e na ausência de cupinicida. Teste do $\chi^{2}(\mathbf{p}<0,05)$

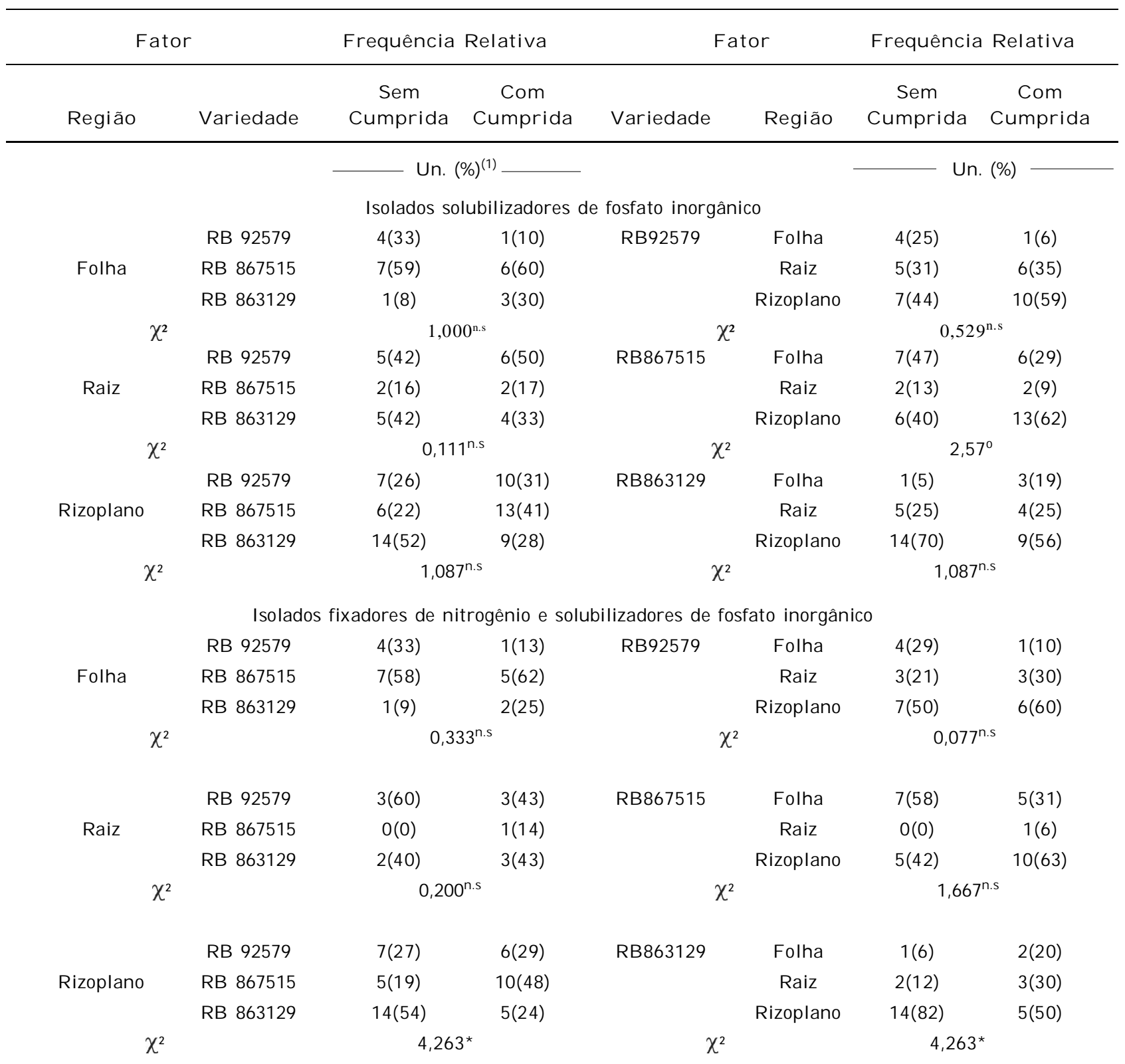

${ }^{(1)}$ Unidade (Un.): representação do valor fora dos parênteses; e percentagem (\%): representação do valor unitário em percentual. ns, ${ }^{\circ}$ e * : não sifnificativo, significativo a 10 e $5 \%$, respectivamente.

\section{CONCLUSÕES}

1. As comunidades bacterianas endofiticas de folha e raiz e epifíticas do rizoplano, em cana-de-açúcar cultivada no Estado de Pernambuco, não apresentaram alterações com a aplicação do cupinicida.

2. As variedades de cana-de-açúcar cultivadas no Nordeste apresentam uma comunidade bacteriana associada com potencial aplicação na promoção de crescimento vegetal, pois foram obtidos isolados mais eficientes em promover o crescimento vegetal na variedade RB 863129 sem aplicação de cupinicida e na RB 867515 com aplicação do cupinicida, onde esses isolados possuem a capacidade de fixar $\mathrm{N}_{2}$ e solubilizar fosfato inorgânico.

\section{AGRADECIMENTOS}

Aos órgãos de fomento CNPq, CAPES e FACEPE, pela concessão de bolsas e custeio do projeto. Aos 
revisores anônimos, pela grande contribuição à melhoria do artigo.

\section{LITERATURA CITADA}

ANDREOTE, F.D. Fatores determinantes na composição da comunidade bacteriana associada às plantas. Piracicaba, Escola Superior de Agricultura "Luiz de Queiroz", 2007. 201p. Tese de Doutorado)

BERGAMASHI, C. Ocorrência de bactérias diazotróficas associadas a raízes e colmos de cultivares de sorgo. Porto Alegre, Universidade Federal do Rio Grande do Sul, 2006. 83p. (Tese de Mestrado)

CANBOLAT, M.Y.; BILEN, S.; CAKMAKCI, R.S.; AHIN, F. \& AYDIN, A. Effect of plant growth-promoting bacteria and soil compaction on barley seedling growth, nutrient uptake, soil properties and rhizosphere microflora. Biol. Fert. Soils, 42:350-357, 2009.

COCKING, E. Endophytic colonization of plant roots by nitrogen-fixing bacteria. Plant Soil, 252:169-175, 2003.

COLLAVINO, M.M.; SANSBERRO, P.A.; MROGINSKI, L.A. \& AGUILAR, O.M. Comparison of in vitro solubilization activity of diverse phosphate-solubilizing bacteria native to acid soil and their ability to promote Phaseolus vulgaris growth. Biol. Fert. Soils, 46:727-738, 2010.

COMPANHIA NACIONAL DE ABASTECIMENTO - CONAB 2010: Acompanhamento da safra brasileira cana-deaçúcar safra 2010/11, $3^{\circ}$ levantamento, janeiro de 2011. Brasília, 2011.

DIAS, A.C.F.; COSTA, F.E.C.; ANDREOTE, F.D.; LACAVA, P.T.; TEIXEIRA, M.A.; ASSUNÇÃO, L.C.; ARAUJO, W.L.; AZEVEDO, J.L. \& MELO, I.S. Isolation of micropropagated strawberry endophytic bacteria and assessment of their potential for plant growth promotion. World J. Microbiol. Biotechnol., 25:189-195, 2009 .

DOBEREINER, J.; BALDANI, V.L.D. \& BALDANI, J.I. Como isolar e identificar bactérias diazotróficas de plantas nãoleguminosas. Brasília, Embrapa - SPI: Itaguaí, RJ/ Embrapa-CNPAB, 1995. 60p.

JHA, B.; THAKUR, M.C.; GONTIA, I.; ALBRECHT, V.; STOFFELS, M.; SCHMID, M. \& HARTMANN, A. Isolation, partial identification and application of diazotrophic rhizobacteria from traditional Indian rice cultivars. Eur. J. Soil Biol., 45: 62-72, 2009.

KHALID, A.; ARSHAD, M. \& ZAHIR, Z.A. Screening plant growth-promoting rhizobacteria for improving growth and yield of wheat. J. Appl. Microbiol., 96:473-480, 2003.

KUKLINSKY-SOBRAL, J.; ARAÚJO, W.L.; MENDES, R.; GERALDI, I.O.; PIZZIRANI-KLEINER, A.A. \& AZEVEDO, J.L. Isolation and characterization of soybean-associated bacteria and their potential for plant growth promotion. Environ. Microbiol., 6:1244-1251, 2004 .
KUNKLINSKY-SOBRAL, J. A comunidade bacteriana endofítica e epifítica de soja (Glycine $\max$ ) e estudo da interação endófitos-planta. Piracicaba, Escola Superior de Agricultura "Luiz de Queiroz", 2003. 174p. (Tese de Doutorado)

MASSENSSINI, A.M.; COSTA, M.D.; REIS, M.R. \& SILVA, A.A. Atividade de isolados bacterianos solubilizadores de fosfato na presença de formulações comerciais de glyphosate. Planta Daninha, 26:815-823, 2008.

MEDEIROS, A.F.A.; POLIDORO, J.C. \& REIS, V.M. Nitrogen source effect on Gluconacetobacter diazotrophicus colonization of sugarcane (Saccharum spp.). Plant Soil, 279:141-152, 2006.

MELLONI, R.; NÓBREGA, R.S.A.; MOREIRA, F.M.S. \& SIQUEIRA, J.O. Densidade e diversidade fenotípica de bactérias diazotróficas endofíticas em solos de mineração de bauxita, em reabilitação. R. Bras. Ci. Solo, 28:85-93, 2004.

MENDES, R.; PIZZIRANI-KLEINER, A.A.; ARAUJO, W.L. \& RAAIJMAKERS, J.M. Diversity of cultivated endophytic bacteria from sugarcane: Genetic and biochemical characterization of Burkholderia cepacia complex isolates. Appl. Environ. Microbiol., 73:7259-7267, 2007.

OLIVEIRA, A.L.M.; STOFFELS, M.; SCHMID, M.; REIS, V.M.; BALDANI, J.I. \& HARTMANN, A. Colonization of sugarcane plantlets by mixed inoculations with diazotrophic bacteria. Eur. J. Soil Biol., 45:106-113, 2009.

PARIONA-LLANOS, R.; FERRARA, F.I.S.; GONZALES, H.H.S. \& BARBOSA, H.R. Influence of organic fertilization on the number of culturable diazotrophic endophytic bacteria isolated from sugarcane. Eur. J. Soil Biol., 46:387-393, 2010.

POLIDORO, J.C.; MEDEIROS, A.F.A.; XAVIER, R.P.; MEDEIROS, J.A.; BODDEY, R.M.; ALVES, B.J.R. \& URQUIAGA, S. Evaluation of techniques for determination of molybdenum in sugarcane leaves. Commun. Soil Sci. Plant Anal., 37:77-91, 2006.

POSTMA, J.; NIJHUIS, E.H. \& SOMEUS, E. Selection of phosphorus solubilizing bacteria with biocontrol potential for growth in phosphorus rich animal bone charcoal. Appl. Soil Ecol., 46:464-469, 2010.

PRAKAMHANG, J.; MINAMISAW, K.; TEAMTAISONG, K.; BOONKERD, N. \& TEAUMROONG, N. The communities of endophytic diazotrophic bacteria in cultivated rice (Oryza sativa L.). Appl. Soil Ecol., 42:141149, 2009.

REIS, M.R.; SILVA, A.A.; GUIMARÃES, A.A.; COSTA, M.D.; MASSENSSINI, A.M. \& FERREIRA, E.A. Ação de herbicidas sobre microrganismos solubilizadores de fosfato inorgânico em solo rizosférico de cana-de-açúcar. Planta Daninha, 26:333-341, 2008.

REIS JÚNIOR, F.B.; SILVA, L.G.; REIS, V.M. \& DOBEREINER, J. Ocorrência de bactérias diazotróficas em diferentes genótipos de cana-de-açúcar. Pesq. Agropec. Bras., 34:985994, 2000.

RICHARDSON, A.E.; BARE, J.M.; MCNEILL, A.M. \& COMBARET, C.P. Acquisition of phosphorus and nitrogen in the rhizosphere and plant growth promotion by microorganisms. Plant Soil, 321:305-339, 2009. 
RODRIGUEZ, H.; GONZALEZ, T. \& SELMAN, G. Expression of a mineral phosphate solubilizing gene from Erwinia herbicola in two rhizobacterial strains. J. Biotecnol., 84:155-161, 2000.

SHI, Y.; LOU, K. \& LI, C. Promotion of plant growth by phytohormone-producing endophytic microbes of sugar beet. Biol. Fert. Soils, 45:645-653, 2009.
VERMA, S.C.; LADHA, J.K. \& TRIPATHI, A.K. Evaluation of plant growth promoting and colonization ability of endophytic diazotrophics from deep water rice. J. Biotecnol., 91:127-141, 2001.

WAKELIN, S.; WARREN, R.; HARVEY, P. \& RYDER, M. Phosphate solubilization by Penicillium spp. closely associated with wheat roots. Biol. Fert. Soils, 40:36-43, 2004. 
R. Bras. Ci. Solo, 36:1113-1121 